Boise State University

ScholarWorks

Organizational Performance and Workplace Learning Faculty Publications and

Presentations
Department of Organizational Performance and Workplace Learning

$11-2019$

\title{
Advancing the Knowledge Base Toward a Comprehensive Model - Part 2: A Holistic Approach to Performance Improvement Practices
}

In Gu Kang

Boise State University

Barbara A. Bichelmeyer

University of Missouri-Kansas City

This is the peer reviewed version of the following article:

Kang, I.G. and Bichelmeyer, B.A. (2019). Advancing the Knowledge Base Toward A Comprehensive Model Part 2: A Holistic Approach to Performance Improvement Practices. Performance Improvement, 58(10), 13-20.

which has been published in final form at doi: 10.1002/pfi.21901 by Wiley on behalf of the International Society for Performance Improvement. This article may be used for non-commercial purposes in accordance with Wiley Terms and Conditions for Self-Archiving. 


\title{
Advancing the Knowledge Base Toward a Comprehensive Model - Part 2: A Holistic Approach to Performance Improvement Practices
}

\author{
In Gu Kang \\ Boise State University
}

\author{
Barbara A. Bichelmeyer \\ University of Missouri-Kansas City
}

\begin{abstract}
This study, the second part of a series of research on advancing the knowledge base toward a comprehensive performance model, discusses the implications on how a theoretically and empirically tested model is put into practice in a more specific way in the light of the three aspects of human resource cognate fields: human performance technology, human resource management, and human resource development.
\end{abstract}

In the first part of this series of research on advancing the knowledge base toward a comprehensive model, we developed a comprehensive framework for a human performance (HP) model by synthesizing the existing HP models in the human performance technology (HPT) field and tested the proposed comprehensive performance model with empirical data. Empirical evidence on the comprehensive HP model in the study strengthens a theoretical basis of the HP model and encourages performance technologists to trust and apply the model to the workplace. Stolovitch (2007) notes that "HPT practices are clearly founded on sound theoretical constructs, scientifically derived evidence, and respectable, well-documented professional precedent” (p. 7). Based on the findings of the model testing, this second part of the study will discuss the implications on how the theoretically and empirically tested model is put into practice in a more specific way in terms of the three aspects of human resource cognate fields: (a) the HPT perspective, (b) the human resource management (HRM) perspective, and (c) the human resource development (HRD) perspective.

\section{The HPT Perspective: HPT Model Testing and the Practical Use of the Model}

The findings of this study contribute to HPT theory or model building in that: (a) for the first time in the HPT field, empirical evidence is provided that the HP model works in the real world; (b) it is a comprehensive HP model; (c) it confirms the seven first-order factors, as well as second-order factors, which both influence performance; and (d) it demonstrates that human behavior (HB) plays a mediating role in the relationship between performance support systems (PSS) and performance.

\section{Implications for Utilization of the HP Model in the Workplace}

Although many great theoretical frameworks for performance have been developed in HPT, the utility of the HP model to the real world has remained questionable because of the lack of empirical evidence to support the model and its elements. The first part of the study empirically tested the comprehensive HP model with first-order and second-order factors. The HPT field is still a relatively young science, and thus much empirical research needs to be conducted to test and build HPT theories and models (Sugrue, 2004) because empirical evidence is how we support these theories and models and provides rationale for practitioners to trust and apply those theories and models. Findings and results for the HP model proposed in this study should encourage HPT professionals to utilize this model in the context of these various work settings by providing empirical evidence to support its theoretical framework and practicality in the workplace.

\section{Implications for a Comprehensive Framework for Performance Improvement}

This study sought to develop and test the comprehensive framework of the HP model. Many scholars have expressed the need for comprehensive systems of various performance practices to overcome the limitations of most efforts to practice performance improvement, which have been fragmented rather than systemic (Becker \& Huselid, 1998; Bichelmeyer \& Horvitz, 2006; Bowen \& Ostroff, 2004; Kling, 1995; Wile, 1996). The model testing in this study applies a systems view to the comprehensive HP model that contains both system factors (e.g., PSS representing environmental elements [EE], organization systems [OS], tools/resources [T/R], and incentives [INC]) and human 
This is an author-produced, peer-reviewed version of this article. The final, definitive version of this document can be found online at Performance Improvement, published by Wiley on behalf of the International Society for Performance Improvement. Copyright restrictions may apply. doi: 10.1002/pfi.21901

behavior factors (e.g., HB representing individual capacity [CAP], knowledge and skills [K/S], and motivation [MOT]). HPT researchers and professionals can use this comprehensive HP model as a starting point when they develop interventions to solve performance problems in the workplace.

\section{Implications for Multidimensional and Multilevel Performance-Related Factors}

The model testing of this study confirmed multidimensional and multilevel performance-related factors including the seven first-order factors (EE, OS, T/R, INC, CAP, K/S, and MOT) and the two second-order factors (PSS and HB) that influence organizational performance. As mentioned earlier, many practices of performance improvement have been done using only single practices separately. This study suggests systems of practices for both performance management (using EE, OS, T/R, and INC) and employee behaviors (using CAP, K/S, and MOT) interventions. For example, when HPT professionals have performance problems or issues, they can take into account both performance support systems and individual human-centered approaches to solving performance problems, based on the multidimensional and multilevel factors recommended in this study. Additionally, they can establish holistic and planned interventions for HPT practices rather than taking a piecemeal approach to dealing with performance problems. From the pragmatic view, this study offers guidelines on various practices for performance improvement based on the seven primary performance factors confirmed in this study. This enables HPT professionals and practitioners to plan specific HRM and HRD practices by providing an integrative view of PSS (system or environment) and HB (behaviors).

\section{Implications for the Structural and Relational Mechanism on Performance Improvement}

Little research on the structural and relational mechanism among PSS, HB, and performance has been conducted, and thereby the mechanism has been ambiguous in both the HPT and HRM fields (Baron, Kruser, \& Huey, 1990; Becker \& Huselid, 1998; Bowen \& Ostroff, 2004; Wile, 1996). The findings of this study reveal the mechanism in which HB acts as a mediator in the relationship between PSS and performance. Having only a good performance support system is not enough for improving performance. Organizations that seek to enhance their success will find the greatest return on investment by working to influence human behavior factors described in this study. Some scholars who take a systems view have overemphasized the relative importance of performance support systems to human behaviors as related to performance improvement. Too much emphasis on performance support systems without taking into account human behavior factors may impede overall organization performance. Therefore, in agreement with the interactional psychology perspective, HPT scholars and practitioners should consider both the systems-view and the peoplecentered perspective when designing and implementing performance improvement initiatives.

Taken together, this study was the first attempt we could find from a review of the literature to empirically test a comprehensive HP model that contains all performance-related factors addressed in the previous HP models from the HPT field. Although many HPT scholars have contributed to the development of HP models during the last several decades, they have not offered empirical evidence on whether their HP models work in the real world. This has been due to the difficulty of gathering a large-scale amount of data to cover the comprehensive framework of the HP model, coupled with the historical lack of advanced statistical techniques to help test the model with empirical data. The empirical evidence from the findings of this study helps to build a foundation for HP theories and further strengthens the theoretical basis of the HPT field.

\section{The HRM Perspective: Planned Interventions for Organization Effectiveness}

As diverse interventions have been well developed in the HRM field, a holistic approach to HRM practices has been a mainstream of HRM-firm relationship research (Bowen \& Ostroff, 2004). In support of this research trend, the findings of this study show that PSS (represented by a set of four different practices such as EE, OS, T/R, and INC) directly and indirectly impact performance. The key here is that four different practices for PSS are thought of not as individual interventions but rather as a collective. HPT and HRM professionals should create systems of performance that include integrated interventions of environment, organization systems, tools and resources, and incentives as planned interventions to support organization effectiveness. Based on the findings of this study, it is meaningful to discuss possible practices for EE, OS, T/R, and INC. 


\section{Implications for EE}

In regard to EE, there are three specific features of physical condition, employees' safety, and ergonomics (Wile, 2014b). First, physical conditions are referred to as sensory elements of environments such as lighting, temperature, and noises. Second, physical safety and security may be more or less important depending on the characteristics of the work. For example, issues of physical safety and security may be more important to labor workers than to professional employees. Third, ergonomics is related to human-factors design of the workspace. All these characteristics of EE may be less likely to directly influence performance improvement than other performance-related factors (Wile, 2014b). However, unreasonable work conditions such as heavy physical work or frequently working overtime may cause health problems and therefore negatively impact organizational performance. Thus, providing proper environmental elements for workers leads to better human performance. HRM professionals should examine the detrimental influences of EE to employees' work such as poor soundproofed workspaces or high-risk areas. To secure the budget for EE, HPT practitioners should prioritize the factors of EE to be improved based on the degree of importance and urgency. Decisions on prioritization need to be agreed upon by stakeholders such as decision makers, employees, and HR professionals. An improved work environment may also have the added benefit of motivating employees.

\section{Implications for OS}

While EE is relatively peripheral to the performance environment that may indirectly influence performance, OS is a set of organizational components that directly impact employees' performance, such as clear performance goals, performance monitoring, rules, and appropriate workloads (Wile, 1996). In this study, three factors were identified as practices for OS: (a) clear agency's goals, (b) performance monitoring, and (c) collaboration support. First, HRM professionals must enable organizations to clearly communicate performance goals within organizations. In so doing, managers play a pivotal role in communicating performance goals between organizations and workers. Managers continue to communicate organizational goals and assess the progress of whether they achieve the goals and objectives. Also, they remind team members of how they are to go about meeting their goals. Individual workers must do the work of attaining organizational goals and set the priorities of their own work to align with the organization's goals. HRM professionals should assess whether goals are clearly communicated among individuals, managers, and organizations. Strategic communication may help HRM professionals clearly communicate and promote organization goals. Strategic communication is the alignment of communication with overall organizational strategies to achieve the goals of the organization (Argenti, Howell, \& Beck, 2005).

Employees' performance should also be monitored by team managers or leaders. From the HRM perspective, organizations need a systematic approach to managing how well jobs or tasks are performed by employees (Anderson, 1996). HRM professionals need to let workers know the status of their performance by regularly monitoring employees' performance. When employees are found to be poor performers, they need support to improve their performance by receiving proper opportunities to learn, such as on-the-job training, certificate or degree programs, and online learning.

In many cases, jobs and projects in the workplace are collaborative works, within teams or between teams rather than individual projects. Yet, groups or teams in organizations often have conflicts about the best ways to achieve their collective goals (Alper, Tjosvold, \& Law, 2000). HRM professionals must act as helpful mediators between conflicting groups or teams. Conflict management transforms the negatives of conflicts into positives by enhancing organizational learning and organizational effectiveness (Rahim, 2002). Therefore, the work of HRM professionals involves helping employees and teams develop the opportunities for organizational learning and achieve effectiveness through conflict management.

\section{Implications for $\mathbf{T} / \mathbf{R}$}

For T/R, certain factors should be considered by HRM practitioners: (a) accessibility, (b) the ability to adjust tools to tasks and work, and (c) maintenance. First, HRM professionals need to identify what tools, hardware, and software are required for specific work. Indeed, many knowledge workers still depend on physical tools such as laptop computers, mobile devices, and printers, and need to easily access these tools. Second, HRM professionals must enable workers to learn how to adjust the tools to their specific work situations. Third, the maintenance of the tools is an important part of increasing the efficacy of the work. For instance, software needs to be upgraded in a timely manner. Likewise, tools are obviously tangible things and thus can be defined by the characteristics of professions (Wile, 
This is an author-produced, peer-reviewed version of this article. The final, definitive version of this document can be found online at Performance Improvement, published by Wiley on behalf of the International Society for Performance Improvement. Copyright restrictions may apply. doi: 10.1002/pfi.21901

2014b). HRM professionals should match lists of tools required to perform to each of the jobs with which they are working. If software tools are updated, workers should be supported to get training programs or self-study on any updates. HRM professionals can also develop job aids or quick tips for tools and send regular newsletters concerning updates or new tools to employees. Based on the three features of tools, they have the opportunities to improve the accessibility, adjustment, and maintenance of tools.

\section{Implications for INC}

With regard to INC, incentives are the surest element of human performance (Wile, 2014b). In this study, two components were used for INC: (a) perceived value and (b) compensation. First, perceived value is related to gaining adequate, honest recognition and positive feedback on performance. Thus, it is a psychological and emotional payoff, rather than a physical or financial one. However, compensation is referred to as financial reward for performance. Promotions, awards, and wage increases are good examples of material compensation. These kinds of incentives are well known to be strong drivers of performance improvement. HRM professionals can utilize both monetary and nonmonetary strategies of incentives to encourage employees to improve performance. Providing profit sharing, pay raises, and bonuses highly motivates employees to engage in their work. Various types of rewards for performance, such as travel tickets and gift cards, let employees competitively perform to win. A fair appraisal of performance satisfies employees in that they desired to be treated fairly and are willing to accept the consequences of fair performance appraisals. Therefore, HRM professionals should make sure that incentives are given in an even-handed manner based on clear criteria of performance evaluation. Otherwise, unfair incentives or lack of incentives may demotivate workers who would otherwise perform well.

\section{The HRD Perspective: Human-Centered Strategies}

Through the testing of the comprehensive HP model in this study, it is found that a plethora of factors related to individual capabilities, job-relevant knowledge and skills, and motivation causes performance behaviors of employees. In addition, only providing organizational performance supports is not enough for improving performance. Humans or employees should act as a mediator to connect organizational performance supports with performance. Humans are referred to as a capital in the HRD field, and its origin can be found in human capital theory (Nafukho, Hairston, \& Brooks, 2004). Human capital theory places emphasis on the improvement of human capability and productivity by making investments in the education of humans (Olaniyan \& Okemakinde, 2008). This principle of human capital theory is consistent with the HRD perspective of developing human resources through training and learning of workers (Nafukho et al., 2004). While scholars in the management field tend to focus too much on managing and supporting workers' performance behaviors, the HRD professionals need to concentrate more on developing human capabilities inherent in human beings with the human-centered view. Based on the results of the model testing in this study, possible human-centered strategies are described in detail for HB (e.g., CAP, K/S, and $\mathrm{MOT}$ ) in the following section.

\section{Implications for CAP}

For CAP, people have the abilities and talents that they are born with and those characteristics are hard to be developed and duplicated (Heinen \& O’Neill, 2004; Wile, 1996). Grasping how their own capabilities and talents can be matched to their own jobs is so important for improving performance. For example, Halvorson and Higgins (2013) present a new perspective on a motivational personality attribute of individuals that influences performance: promotion-focus and prevention-focus. Promotion-focused workers are those who seek to achieve goals, work quickly and creatively, and create new opportunities; prevention-focused employees are those who refer to the goals as responsibilities, work slowly and intentionally, and are risk-averse (Halvorson \& Higgins, 2013). Once individuals understand their own motivational focus, they need to establish motivational strategies to maximize their performance. In the meantime, all duties and responsibilities to manage the characteristics of employees mainly fall to the management. With the employee perspective, each employee needs to actively identify his or her own motivational traits and the HRD professionals have to help them find the best motivational fit for their tasks.

\section{Implications for $\mathrm{K} / \mathrm{S}$}

In regard to K/S, there is no doubt that developing job-relevant knowledge and skills is one of the most obvious elements for human performance (Wile, 2014a). For this reason, training and development has been one of the major functions of HRD (Werner \& DeSimone, 2006). There are many ways to develop knowledge and skills required to 
This is an author-produced, peer-reviewed version of this article. The final, definitive version of this document can be found online at Performance Improvement, published by Wiley on behalf of the International Society for Performance Improvement. Copyright restrictions may apply. doi: 10.1002/pfi.21901

attain goals such as education, training, and informal learning. First, education is a more long-term perspective to employee development than training (Wile, 2014a). From a corporate standpoint, education may be an expensive way of developing the knowledge and skills of employees. However, while training tends to focus too much on specific knowledge and skills, education can offer the lifelong educational opportunities to explore a career plan to become a leading expert. Second, training is the most typical way of providing workers with knowledge and skills necessary for specific jobs and tasks in most organizations (Werner \& DeSimone, 2006). Although training is regarded not as investments but costs in many companies, it is the preferred means of acquiring knowledge and skills in the workplace. Third, unlike formal learning, informal learning occurs in situations that are not classroom-based (Marsick \& Watkins, 2001). Some scholars suggest that informal learning is increasingly more dominant than formal learning in the workplace (Boud \& Middleton, 2003).

For formal learning such as education and training, an organization needs to identify the training needs of employees by aligning with business needs and individual needs to successfully attain organizational goals. Training needs analysis is essential for developing successful training programs and gives four benefits in that the HRD professionals can (a) identify the current problems of training programs, (b) get managerial support and give a positive impression on training, (c) accumulate the evaluation data on training programs, and (d) offer reasonable costs and expected benefits of training (Brown, 2002). Taylor, O’Driscoll, and Binning (2006, p. 29) suggest two different approaches to training needs analysis of "task-focused training" for job-specific knowledge and skills and "results-focused training" for increasing organizational outcomes. Along with these two approaches, the HRD professionals can urge employees to acquire knowledge and skills required for jobs. For task-focused training, the HRD professionals can encourage workers to gain job-specific knowledge and skills by providing typical training programs such as offsite, onsite, or online learning. For results-focused training, the HRD professionals can provide action learning, a tool for leadership and organization development, for employees to develop problem-solving skills and meta-cognitive skills for learning (Park, Kang, Valencic, \& Cho, 2012). The strategic approaches to training needs analysis enhance different levels of knowledge and skills needed for their work.

However, to enhance informal learning, English (2000) suggests three strategies of informal learning: (a) mentoring, (b) self-directed learning, and (c) dialogue. First, mentorship is a type of informal learning relying on the interpersonal relationship between a mentor and mentee. Employees can have ongoing support on work-related problems, career development, and even psychological issues. Second, self-directed learning is "an approach where learners are motivated to assume personal responsibility and collaborative control of the cognitive (self-monitoring) and contextual (self-management) processes” (Garrison, 1997, p. 18). Employees themselves increase capacities to learn informally through self-directed learning. Third, dialogue is a good strategy of informal learning in that it helps promote collaboration and partnership and is key to improving organizational effectiveness (English, 2000). Therefore, the HRD professionals can provide a system or structure in which employees have various informal learning opportunities and become self-directed learners (Marsick \& Watkins, 2001).

\section{Implications for MOT}

For MOT, motivating workers in organizations always has been a major concern for managers and leaders since motivated workers are willing to put extra effort into their jobs and tasks (Amabile, 1993). Intrinsic motivation, one of the two types of human motivation, is hard for managers or leaders to influence and develop (Wile, 2014a). Thomas (1985) indicates that organizations that overemphasize the management functions to motivate employees overlook the fact that motivation is a matter of individuals. In a study of intrinsic motivation inventory, Markland and Hardy (1997) confirm the four dimensions of intrinsic motivation: (a) perceived competence, (b) interest-enjoyment, (c) pressuretension, and (d) effort-importance. In the current study, two dimensions of "interest-enjoyment" and "effortimportance" were taken into account. First, workers who are intrinsically motivated are willing to put in extra effort to attain goals by looking for better ways to do things by themselves. The amount of extra effort put into their work is consistent with the level of intrinsic motivation of individuals. Second, intrinsically motivated people like and enjoy the work they do. That is, they are satisfied by their work itself, regardless of extrinsic rewards.

McAuley, Wraith, and Duncan (1991) point out that self-efficacy of individuals promotes intrinsic motivation. Thus, enhancing self-efficacy may be helpful for increasing intrinsic motivation. Self-efficacy is referred to as "one's belief system” in capabilities to accomplish tasks and achieve goals (Driscoll, 1994). In his self-efficacy theory, Bandura (1977) presents the four sources of affecting self-efficacy: (a) enactive mastery experiences, (b) vicarious experience, (c) verbal persuasion, and (d) physiological states. People, for example, have their self-efficacy beliefs by having their own success stories about tasks (mastery experiences), looking for a role model for their own works (vicarious 
This is an author-produced, peer-reviewed version of this article. The final, definitive version of this document can be found online at Performance Improvement, published by Wiley on behalf of the International Society for Performance Improvement. Copyright restrictions may apply. doi: 10.1002/pfi.21901

experiences), listening to others' advice that they have enough capabilities to complete tasks (verbal persuasion), and identifying their own arousal states about the positive feeling of their tasks (physiological states). Using these sources of self-efficacy, the HRD professionals can encourage employees to have high self-efficacy by giving challenging yet attainable tasks so that employees can have the opportunities to experience success on their tasks. Also, the HRD professionals can develop and share a role model for particular tasks or fields so workers pursue a successful career path of a role model. In addition, the HRD professionals can offer mentoring systems where employees can get useful advice to help succeed in their tasks. Although internal motivation of individuals is somewhat difficult to generate, self-efficacy is meant to be a generative ability (Bandura, 1977; Driscoll, 1994). Consequently, the strategies for selfefficacy have an influence on promoting internal motivation of employees.

\section{Conclusions}

In the second part of this study, we took a closer look at the implications on how the theoretically and empirically proven HP model can be applied to a real workplace setting in terms of the HPT, HRM, and HRD perspectives. Ruona and Gibson (2004) note that "contributing strategically to organizations demands that HRM, HRD, and OD [i.e., HPT] coordinate, partner, and think innovatively about how they relate and how what they do impacts people and organizations" (p. 49). The comprehensive framework for the HP model proposed in this study can play a key role in bridging theory, research, and practice across the HPT, HRM, and HRD fields. In addition, as a performance problem becomes more complex and complicated, the comprehensive HP model is more appropriate for better understanding a performance situation and finding the best solution to a performance problem. The empirically proven HP model will increase the applicability of the HP model to a real workplace performance situation.

\section{References}

Alper, S., Tjosvold, D., \& Law, K. S. (2000). Conflict management, efficacy, and performance in organizational teams. Personnel Psychology, 53, 625-642. doi: 10.1111/j.1744-570.2000.tb00216.x

Amabile, T. M. (1993). Motivational synergy: Toward new conceptualizations of intrinsic and extrinsic motivation in the workplace. Human Resource Management Review, 3, 185-201. http://dx.doi.org/10.1016/10534822(93)90012-S

Anderson, G. (1996). Performance appraisal. In B. Towers (Ed.), Handbook of human resource management (pp. 196-222). Oxford, UK: Blackwell.

Argenti, P. A., Howell, R. A., \& Beck, K. A. (2005). The strategic communication imperative. MIT Sloan Management Review, 46(3), 83-89. Retrieved from http://sloanreview.mit.edu/

Bandura, A. (1977). Self-efficacy: Toward a unifying theory of behavioral change. Psychological Review, 84, 191215. doi: 10.1037/0033-295X.84.2.191

Baron, S., Kruser, D., \& Huey, B. M. (1990). Quantitative modeling of human performance in complex, dynamic systems. Washington, DC: National Academy Press.

Becker, B. E., \& Huselid, M. A. (1998). High performance work systems and firm performance: A synthesis of research and managerial implications. In G. R. Ferris (Ed.), Research in personnel and human resource management (pp. 53-101). Greenwich, CT: JAI Press Inc.

Bichelmeyer, B. A., \& Horvitz, B. S. (2006). Comprehensive performance evaluation: Using logic models to develop a theory-based approach for evaluation of human performance technology interventions. In J. A. Pershing (Ed.), Handbook of human performance technology: Principles, practices, and potential (pp. 1165-1189). San Francisco, CA: Pfeiffer.

Boud, D., \& Middleton, H. (2003). Learning from others at work: Communities of practice and informal learning. Journal of Workplace Learning, 15, 194-202. doi: 10.1108/13665620310483895

Bowen, D. E., \& Ostroff, C. (2004). Understanding HRM-firm performance linkages: The role of the "strength" of the HRM system. Academy of Management Review, 29, 203-221. http://dx.doi.org/10.5465/AMR.2004.12736076

Brown, J. (2002). Training needs assessment: A must for developing an effective training program. Public Personnel Management, 31, 569-578. doi: 10.1177/009102600203100412

Driscoll, M. E. (1994). Psychology of learning for instruction (3rd ed.). Boston, MA: Allyn and Bacon.

English, L. M. (2000). Spiritual dimensions of informal learning. In L. M. English and M. Gillen (Eds.), Addressing the spiritual dimensions of adult learning: What educators can do (pp. 29-38). San Francisco, CA: JosseyBass. 
This is an author-produced, peer-reviewed version of this article. The final, definitive version of this document can be found online at Performance Improvement, published by Wiley on behalf of the International Society for Performance Improvement. Copyright restrictions may apply. doi: 10.1002/pfi.21901

Garrison, D. R. (1997). Self-directed learning: Toward a comprehensive model. Adult Education Quarterly, 48, 1833. doi: $10.1177 / 074171369704800103$

Halvorson, H. G., \& Higgins, E. T. (2013). Do you play to win—or to not lose? Harvard Business Review, 91(3), 117-120. Retrieved from https://hbr.org/

Heinen, J. S., \& O’Neill, C. (2004). Managing talent to maximize performance. Employment Relations Today, 31, 67-82. doi: 10.1002/ert.20018

Kling, J. (1995). High performance work systems and firm performance. Monthly Labor Review, 118(5), 29-36. Retrieved from http://www.bls.gov/opub/mlr/home.htm

Markland, D., \& Hardy, L. (1997). On the factorial and construct validity of the intrinsic motivation inventory: Conceptual and operational concerns. Research Quarterly for Exercise and Sport, 68, 20-32. doi: 10.1080/02701367.1997.10608863

Marsick, V. J., \& Watkins, K. E. (2001). Informal and incidental learning. In S. B. Merriam (Ed.), The new update on adult learning theory (pp. 25-34). New Directions for Adult and Continuing Education, No. 89. San Francisco, CA: Jossey-Bass.

McAuley, E., Wraith, S., \& Duncan, T. E. (1991). Self-efficacy, perceptions of success, and intrinsic motivation for exercise. Journal of Applied Social Psychology, 21, 139-155. doi: 10.1111/j.1559-1816.1991.tb00493.x

Nafukho, F. M., Hairston, N. R., \& Brooks, K. (2004). Human capital theory: Implications for human resource development. Human Resource Development International, 7, 545-551. doi: $10.1080 / 1367886042000299843$

Olaniyan, D. A., \& Okemakinde, T. (2008). Human capital theory: Implications for educational development. Pakistan Journal of Social Sciences, 5(5), 479-483. Retrieved from http://www.medwelljournals.com/journalhome.php?jid=1683-8831

Park, S., Kang, I.-G., Valencic, T. R., \& Cho, Y. (2012). Why are we using action learning and in what contexts? Action Learning: Research and Practice, 10, 4-24. doi: 10.1080/14767333.2012.744299

Rahim, M. A. (2002). Toward a theory of managing organizational conflict. The International Journal of Conflict Management, 13, 206-235. doi: 10.2139/ssrn.437684

Ruona, W. E., \& Gibson, S. K. (2004). The making of twenty-first-century HR: An analysis of the convergence of HRM, HRD, and OD. Human Resource Management, 43, 49-66. http://dx.doi.org/10.1002/hrm.20002

Stolovitch, H. D. (2007). Human performance technology: Research and theory to practice. Performance Improvement, 39(4), 7-16. https://doi.org/10.1002/pfi.4140390407

Sugrue, B. (2004). Validated practice: The research base for performance improvement. Performance Improvement, 43, 8-13. http://dx.doi.org/10.1002/pfi.4140430605

Taylor, P. J., O’Driscoll, M. P., \& Binning, J. F. (2006). A new integrated framework for training needs analysis. Human Resource Management Journal, 8, 29-50. doi: 10.1111/j.1748-8583.1998.tb00165.x

Thomas, P. G. (1985). Advanced psycho cybernetics and psycho feedback. San Francisco, CA: Classic.

Werner, J. M., \& DeSimone, R. L. (2006). Human resource development (4th ed.). Mason, OH: ThomsonSouthwestern.

Wile, D. E. (1996). Why doers do. Performance \& Instruction, 35(2), 30-35. Retrieved from http://www.ispi.org/

Wile, D. E. (2014a). Why doers do-Part 1: Internal elements of human performance. Performance Improvement, 53, 14-20. doi: $10.1002 /$ pfi.21394

Wile, D. E. (2014b). Why doers do-Part 2: External-tangible elements of human performance. Performance Improvement, 53, 5-13. doi: 10.1002/pfi.21398

\section{About the Authors}

In Gu Kang, $\mathrm{PhD}$, is an assistant professor in the department of Organizational Performance and Workplace Learning (OPWL) in the College of Engineering at Boise State University (BSU). Kang holds a PhD in Instructional Systems Technology at Indiana University Bloomington. Before joining OPWL at BSU, Kang worked as a learning analytic associate in the Center for Educational Innovation at the State University of New York at Buffalo from 2015 to 2017. Kang also worked at Korea Productivity Institute, an affiliation of the Korean government, as a human resource development consultant and e-learning professional from 2006 to 2008. His research interests include human performance technology model testing and development, performance interventions, organizational performance and development, public health workforce, and learning analytics using advanced statistical methods such as mediation analysis, exploratory and confirmatory factor analysis, structural equation modeling, and latent class analysis. He may be reached at ingukang@boisestate.edu. 
This is an author-produced, peer-reviewed version of this article. The final, definitive version of this document can be found online at Performance Improvement, published by Wiley on behalf of the International Society for Performance Improvement. Copyright restrictions may apply. doi: 10.1002/pfi.21901

Barbara A. Bichelmeyer, PhD, currently serves as provost and executive vice chancellor at the University of MissouriKansas City (UMKC). Prior to joining UMKC in August 2015, Bichelmeyer held several roles at Indiana University, including executive associate vice president for University Academic Affairs and senior director of the Office of Online Education. She also spent a year as interim chancellor of Indiana University Southeast. Her research and grant activities are focused on studying how educational systems integrate new technologies and how the introduction of new technologies changes educational systems to better support student-centered learning and improved human performance. She has served as a consultant for the design, development, and evaluation of instructional programs and performance improvement initiatives with numerous organizations. She holds four degrees from the University of Kansas (KU): BS in Journalism; BA in English; MS in Educational Policy and Administration; and a PhD in Educational Communications and Technology. She may be reached at bichelmeyer@umkc.edu.

\section{Two Pull Quotes}

"HPT practices are clearly founded on sound theoretical constructs, scientifically derived evidence, and respectable, well-documented professional precedent.”

(Stolovitch, 2007, p. 7).

"Contributing strategically to organizations demands that HRM, HRD, and OD [i.e. HPT] coordinate, partner, and think innovatively about how they relate and how what they do impacts people and organizations."

(Ruona and Gibson, 2004, p. 49) 